\title{
Impact of high-frequency nonlinear internal waves on plankton dynamics in Massachusetts Bay
}

\author{
by Zhigang Lai ${ }^{1,2}$, Changsheng Chen ${ }^{1,3}$, Robert C. Beardsley ${ }^{4}$, Brian Rothschild ${ }^{1}$ \\ and Rucheng Tian ${ }^{1}$
}

\begin{abstract}
A simple Nutrient-Phytoplankton-Zooplankton (NPZ) model was coupled with the nonhydrostatic Finite-Volume Coastal Ocean Model (FVCOM-NH) to study the impact of highfrequency nonlinear internal waves on plankton dynamics in Massachusetts Bay (MB) during the stratified summer season. The temporal and spatial variability of phytoplankton concentration follows the vertical isopycnal displacement to the lowest order as the waves are generated by the semidiurnal tidal flow over Stellwagen Bank (SB) and propagate westward across MB. The tidally-averaged distribution of phytoplankton is characterized by three distinct zones of low subsurface concentration: (I) the western flank of Stellwagen Bank; (II) the center of Stellwagen Basin; and (III) the upper western flank of Stellwagen Basin. The result of a model dye experiment suggests that these zones are created by the following physical processes which are dominant in each zone: (I) hydraulic jump; (II) strong internal wave-tidal current nonlinear interaction; and (III) energetic internal wave dissipation and subsequent mixing processes. The nonlinear interaction of the internal waves and offshore tidal currents significantly enhances the vertical velocity, and increases wave dissipation, thus causing an onshore transport of phytoplankton in zone II. Although the phytoplankton patchy structure can be produced using the hydrostatic FVCOM, the resulting phytoplankton concentration is overestimated due to the unrealistic intensification of vertical velocity and thus vertical nutrient flux from the deep water. It suggests that non-hydrostatic dynamics should be considered for certain small-scale biological processes that are driven primarily by the physics.
\end{abstract}

\section{Introduction}

Our current understanding of the impact of large amplitude, high-frequency nonlinear internal waves on plankton distribution in Massachusetts Bay (MB) is based on the early study of Haury et al. (1979, 1983) (Fig. 1). They suggested that the westward propagating internal wave packet observed in MB originates from a single large lee wave on the eastern

1. Department of Fisheries Oceanography,School for Marine Science and Technology, University of Massachusetts-Dartmouth, New Bedford, Massachusetts, 02744, U.S.A.

2. Corresponding author.email:z.lai@umassd.edu

3. Marine Ecosystem and Environment Laboratory, College of Marine Science, Shanghai Ocean University, Shanghai, P. R. China.

4. Department of Physical Oceanography, Woods Hole Oceanographic Institution, Woods Hole, Massachusetts, 02543, U.S.A. 


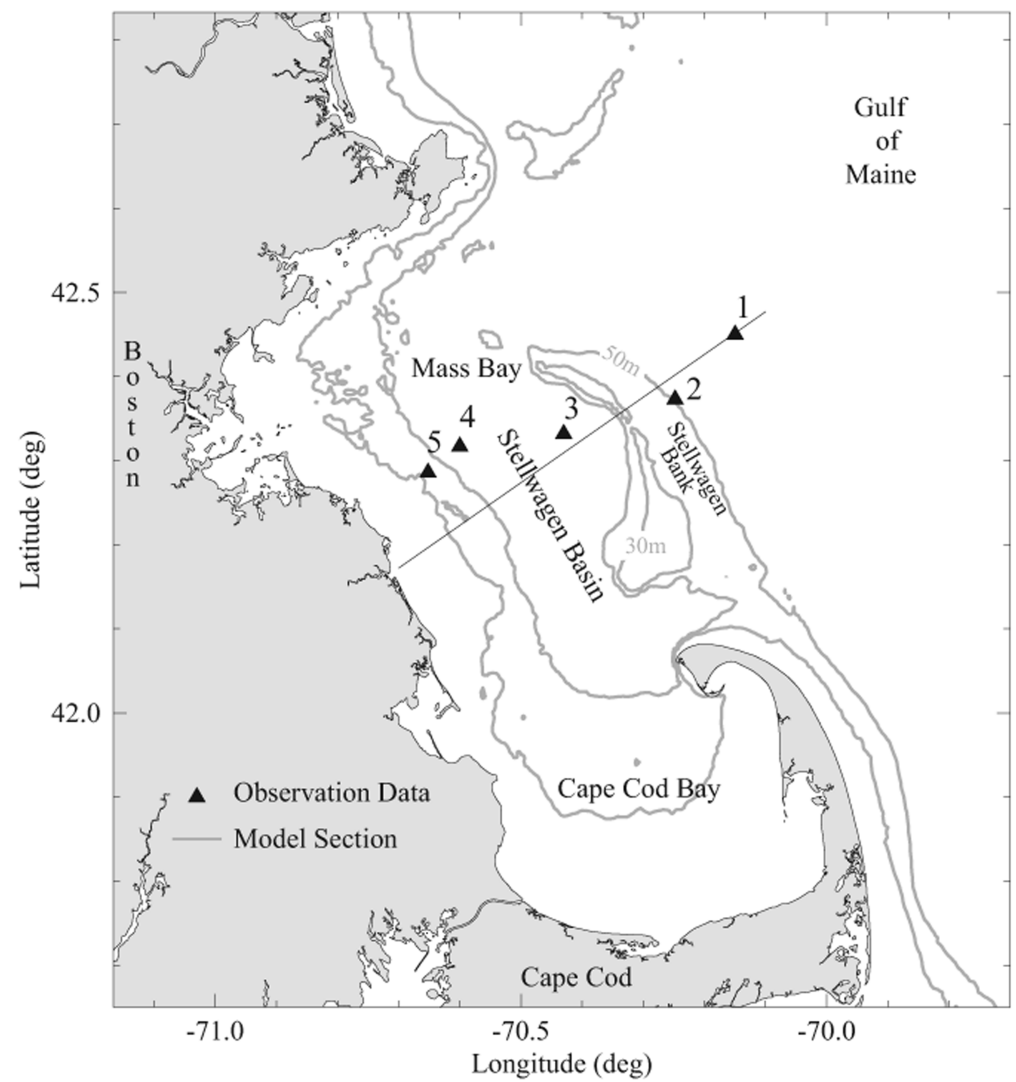

Figure 1. Schematic of Massachusetts Bay (MB), Stellwagen Bank (SB), and the transect used to construct the two-dimensional numerical model. Filled triangles \#1-5 show the locations of in-situ phytoplankton data obtained from NODC.

side of Stellwagen Bank (SB), in line with Maxworthy's theory (1979) for the topographic generation of internal waves. The lee wave is formed under supercritical flow conditions on the Bank during ebb tide (eastward semidiurnal tidal current) and propagates upstream against the slackening ebb tidal current at the turning of the tidal phase. Under this framework, Haury et al. (1979) schematized the temporal and spatial patterns of plankton that are passively displaced in the vertical and horizontal following isotherm oscillations as the internal wave packet evolves over SB and in MB. This scenario has been widely used in textbooks and cited in literature as a classic pattern of plankton within an internal wave packet (Le Fèvre, 1987; Daly and Smith, 1993; Thorpe, 2005).

Whether or not Maxworthy's theory is applicable to MB has been questioned in previous and recent modeling studies. Hibiya (1988) first pointed out that the high-frequency internal waves in $\mathrm{MB}$ were not generated by a simple quasi-steady lee wave process. Recently, a comprehensive field study of the high-frequency internal waves in MB was 
conducted in August 1998 (referred as MBIWE98) (Butman et al., 2006). Although the measurements did not cover the region of wave generation over SB, the data collected in MB provided an excellent foundation for model comparison and validation. Using a two-dimensional (2D) inviscid streamfunction-vorticity model validated with MBIWE98 data, Scotti et al. $(2007,2008)$ suggested that the observed internal wave packet in MB starts as a density depression over the eastern slope of SB during ebb tide. They disputed the lee wave mechanism in that it is the relaxation of the density depression rather than the upstream propagation of the lee wave that generates the internal waves. Lai et al. (2010b) applied the unstructured-grid Finite-Volume primitive equation Non-Hydrostatic Coastal Ocean Model (FVCOM-NH) to examine the physical process during the early stages of internal wave generation over SB. They found that the internal waves over SB are generated through the formation of an initial density front on the western flank near the ebb-flood transition; steepening of the front as the density depression develops in early flood phase on the bay-side slope of SB; and disintegration of the density depression into a wave packet. This finding concurs with the generation process of internal wave theory proposed by Lee and Beardsley (1974), and is evident in a recent series of intensive internal wave surveys in MB led by K. Shearman and J. Lerczak (Oregon State University) (personal comm.).

Although the internal wave theory used to schematize plankton patchiness in MB by Haury et al. $(1979,1983)$ is not generally applicable, their observations within an internal wave packet did show that internal waves have a strong impact on plankton distribution. For example, it was found that phytoplankton and zooplankton were passively displaced in the vertical following the isotherm oscillations during the passage of internal wave packets. The vertical displacement of phytoplankton can cause a change in light level in a range of $74 \%$ between the wave crest and trough. This rapid change in the light environment persists for 1-2 hours every semidiurnal period and was expected to have a significant influence on primary productivity in MB (Haury et al., 1979, 1983). The observations also detected local overturning events of internal waves in the deep interior of MB. As a result of mixing-induced upward nutrient fluxes, small patchy structures of plankton formed within the wave packets.

There have been many studies aimed at internal wave-induced physical-biological interactions. Examples include Shanks (1983), Kingsford and Choat (1986), Lamb (1997), and Pineda (1999), who examined the shoreward transport of fish larvae by internal tidal bores or internal waves; Sandstorm and Elliott (1984), who reported that internal tides and waves can be a physical mechanism for the cross-shelf transport of nutrients; Witman et al. (1993) and Franks and Chen (1996), who pointed out that a large vertical displacement of internal tides and waves can act as a food transfer mechanism to dump the phytoplanktonrich water downward to the benthos on subtidal pinnacles; Lennert-Cody and Franks (1999, 2002), who explored how swimming behavior or non-photochemical quenching of plankton produces the chlorophyll fluorescence patches in high-frequency internal waves; Evans et al. (2008), who found that the vertical displacement of phytoplankton in a 
nonlinear light field of interval waves could enhance photosynthesis in an oligotrophic lake; Sangrà et al. (2001), who reported that internal wave-induced mixing could play a major role in the nutrient supply from deep water into the euphotic zone.

To our knowledge, little work has been conducted to examine how the physicalbiological interaction processes contribute to plankton patchiness on a regional scale covering the entire cycle of high-frequency internal waves: their origin, propagation, shoaling and dissipation. Since the perturbations caused by internal waves on their journey of propagation are seldom uniform in space (e.g., wave shoaling over inclined topography or the interactions of waves with large-scale tidal currents), it is suspected that the patchy structure of plankton within the area affected by internal waves may involve more complex physics in addition to wave-induced small-scale variation in mixing and high-frequency isopycnal vertical displacement. In particular, in MB it remains unknown whether the plankton patches detected in the internal wave measurements are caused solely by local biophysical interactions or also transported with the waves from their origin. It is also unclear whether the rapid change of light within internal waves could have a significant effect on plankton production and whether or not this can be quantitatively estimated using a model.

A non-hydrostatic version of the unstructured-grid Finite-Volume Coastal Ocean Model (FVCOM-NH) was developed by Lai et al. (2010a). This model has succeeded in reproducing the generation, propagation and shoaling of both internal tides and largeamplitude high-frequency nonlinear internal waves observed during summer time in $\mathrm{MB}$ (Lai et al., 2010b). Using a simple Nutrient-Phytoplankton-Zooplankton (NPZ) food-web model coupled with FVCOM-NH, we have examined the impact of physical processes on the temporal variation and spatial distribution of plankton in MB. A detailed description and discussion of the experimental results are given here, with a focus on quantifying the respective contributions of various physical and biological processes to the formation of plankton patchiness over SB, in Stellwagen Basin, and over the MB shelf.

\section{Non-hydrostatic coupled physical and biological model}

High-frequency internal waves over SB are generated through the nonlinear interaction of tides with steep bottom topography. During the wave evolution, the vertical motion of the flow can be comparable to local depth and the vertical velocity is of the same order of magnitude as the horizontal velocity. As a result, non-hydrostatic dynamics directly contributes to the internal wave process in MB (Lee and Beardsley, 1974; Maxworthy, 1979; Hibiya, 1988; Scotti et al., 2007; Lai et al., 2010b).

FVCOM-NH is the non-hydrostatic model selected for this study. By representing correctly the balance between nonlinearity and dispersion during the wave evolution under non-hydrostatic conditions, this model is capable of simulating the large-amplitude high-frequency nonlinear internal waves in MB (Lai et al., 2010b). FVCOM-NH was developed by adding non-hydrostatic dynamics into FVCOM (Lai et al., 2010a), an advanced hydrostatic model developed originally by Chen et al. (2003) and updated 
through a team effort (Chen et al., 2006a, b; 2007; Huang et al., 2008). The details of the governing equations, numerical algorithms and discrete methods of FVCOM-NH were described by Lai et al. (2010a). The model is coded with MPI-based parallelization (Cowles, 2008), and the non-hydrostatic pressure equation is solved numerically using a parallelized, scalable, sparse matrix solver library (PETSc) (Balay et al., 2007) with a high-performance pre-conditioner library (Hypre) (Falgout and Yang, 2002). These technologies guarantee an optimal computational efficiency under the high-performance multi-processor environment which is critical in tackling the large dimensional size associated with the non-hydrostatic flow.

For this idealized mechanism study, we constructed the biological model based on the simple Nutrient-Phytoplankton-Zooplankton (NPZ) food web dynamics developed by Franks et al. (1986) and Franks and Chen (1996). The governing equations of the NPZ model are given as

$$
\begin{gathered}
\frac{d P}{d t}=\frac{V_{m} N}{K_{s}+N} f\left(I_{0}\right) P-Z R_{m}\left(1-e^{-\lambda P}\right)-\varepsilon P+\left(F_{P}\right)_{z} \\
\frac{d Z}{d t}=\gamma Z R_{m}\left(1-e^{-\lambda P}\right)-g Z+\left(F_{Z}\right)_{z} \\
\frac{d N}{d t}=-\frac{V_{m} N}{K_{s}+N} f\left(I_{0}\right) P+(1-\gamma) Z R_{m}\left(1-e^{-\lambda P}\right)+\varepsilon P+g Z+\left(F_{N}\right)_{z}
\end{gathered}
$$

where $N, P$ and $Z$ are nutrients, phytoplankton and zooplankton, respectively, in mmol N $\mathrm{m}^{-3} ; F_{P}, F_{Z}$ and $F_{N}$ represent the diffusion terms in the $P, Z$ and $N$ equations, respectively, and subscript " $z$ " indicates the vertical component. The vertical diffusion coefficient was specified as a constant value of $1 \times 10^{-6} \mathrm{~m}^{2} \mathrm{~s}^{-1}$. Nitrogen is taken as the tracer of state variables. Nutrient uptake is based on the Michaelis-Menten kinetics, while zooplankton grazing on phytoplankton is parameterized by the Ivlev functional equation.

The seven controlling parameters in Eqs. (1)-(3) include: maximum phytoplankton growth rate, $V_{m}\left(2.0 \mathrm{~d}^{-1}\right)$; phytoplankton half-saturation constant $K_{s}\left(1.0 \mathrm{mmol} \mathrm{N} \mathrm{m}{ }^{-3}\right)$; phytoplankton death rate, $\varepsilon\left(0.1 \mathrm{~d}^{-1}\right)$; zooplankton maximum grazing rate $R_{m}\left(0.5 \mathrm{~d}^{-1}\right)$, zooplankton death rate, $g\left(0.1 \mathrm{~d}^{-1}\right)$, Ivlev constant $\lambda$ for grazing $\left(0.2 \mathrm{mmol} \mathrm{N} \mathrm{m}{ }^{-3}\right)$ and zooplankton assimilation efficiency $\gamma$ for phytoplankton ( 0.7 dimensionless). The parameter values used here are adopted from Franks and Chen (2001). In the model, the dead phytoplankton, zooplankton and the unassimilated portion of zooplankton grazing are assumed to be immediately recycled into dissolved nutrients. This assumption is made with an understanding that the recycling process during summer in $\mathrm{MB}$ is faster in comparison to spring bloom conditions and our studies are focused on the impacts of high-frequency internal waves on the spatial distribution of phytoplankton. The vertical light dependence of phytoplankton growth is parameterized as

$$
f\left(I_{0}\right)=I_{0} e^{k_{e x} Z}
$$


where $z$ is the water depth, $I_{0}$ is the normalized surface light intensity taken as a constant value of 1.0 during the model run (Franks and Chen, 2001), and $k_{\text {ext }}$ is the attenuation coefficient for irradiance which is chosen as $0.17 \mathrm{~m}^{-1}$ according to in situ observation (Haury et al., 1979, 1983). The sinking velocity of phytoplankton in the water column is specified as $1.0 \mathrm{~m} \mathrm{~d}^{-1}$.

The NPZ model is coded using the Generalized Biological Module (GBM) in FVCOM (Chen et al., 2006a). The GBM was developed following a strategy to include finite numbers of various biological variables and energy transformation processes of the lower trophic level food web system under the parallelized, unstructured-grid finite-volume platform. This module allows users either to select a pre-built biological model (such as NPZ, NPZD, etc.) or to construct their own biological model using the pre-defined pool of biological variables and parameterization functions.

\section{Design of numerical experiments}

The coupled FVCOM-NH-NPZ model was configured for a two-dimensional (2D) computational domain in which $(x, z)$ is defined as the cross-bank and vertical axes, respectively. This domain represents a transect perpendicular to Stellwagen Bank, running from the eastern side of SB to the Massachusetts coast (Fig. 1). The horizontal resolution varies in space, with the finer grid of $20 \mathrm{~m}$ in a region covering the wave generation, propagation and shoaling/dissipation, and the coarser grid of $200 \mathrm{~m}$ near the open boundary and coastal region (Fig. 2). A linear transition zone is used to link the fine- and coarse-grid regions. This grid configuration is designed to resolve the internal waves inside MB for a relatively long-time integration with little sacrifice in computational efficiency. In the vertical, 45 uniform sigma layers are used, which corresponds to a vertical resolution of $\sim 2 \mathrm{~m}$ in the deepest region and $\sim 0.7 \mathrm{~m}$ at the crest of SB.

The internal waves in MB are generated by the nonlinear interaction of semi-diurnal tides with local topography of SB. The FVCOM-NH-NPZ model was driven by the $\mathrm{M}_{2}$ tidal forcing with amplitude of $1.8 \mathrm{~m}$ at the eastern (open ocean) boundary. The tidal amplitude used here corresponds to the average semidiurnal spring tide. Field observations show that after the internal waves shoaled over the shallow shelf off the Massachusetts coast, their energy was transferred in the along-coast direction with little reflection back to the interior of MB (Butman et al., 2006; Scotti et al., 2007). To avoid wave reflection on the coastal boundary in our 2D model, a gravity wave radiation condition was specified at the western (coastal) boundary to allow the tidal wave to propagate out of the computational domain with minimum reflection. A sponge layer with a coefficient of damping of 0.0013 is added in a zone connected to this boundary to absorb the outgoing internal wave energy.

The initial density field was adopted from a profile that fits the observed August stratification in MB (Fig. 3) (Scotti et al., 2007; Lai et al., 2010b). For simplification, we assumed that the initial density $(\rho)$ is linearly proportional to salinity $(S)$, so that 


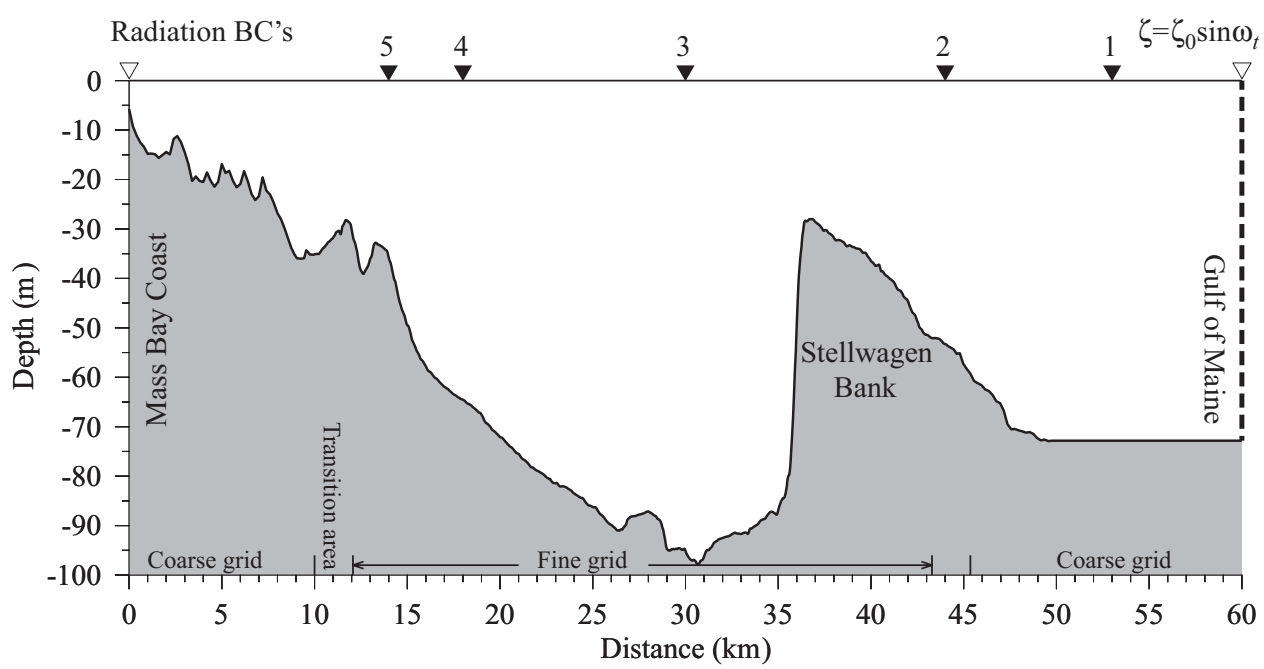

Figure 2. Bathymetry of the cross-bay transect shown in Figure 1. The model is driven by tidal forcing specified as $\zeta=\zeta_{o} \sin \omega t$ at the open boundary (right). Here, $\zeta$ is the free surface elevation and $\zeta_{o}$ and $\omega$ are the amplitude and frequency of the $\mathrm{M}_{2}$ tide. A gravity wave radiation boundary condition is specified on the shore-side boundary (left) under the assumption that zero energy reflects back into the interior from the coast. The computational domain features a non-uniform horizontal grid (see text for details). Labels \#1-5 are the locations of the measurement sites which are interpolated to the transect assuming no along-isobath variation (also shown in Fig.1). The transition between Stellwagen Basin and the shallower MB "shelf" that extends to the coast occurs at $\sim 13 \mathrm{~km}$ from the coast.

$$
\rho=999.972 \times\left(1+0.75 \times 10^{-3} S\right) .
$$

In this 2D study, FVCOM-NH included the earth's rotation (Coriolis acceleration) and a constant vertical turbulence diffusivity $K_{m}$ of $2 \times 10^{-5} \mathrm{~m}^{2} \mathrm{~s}^{-1}$ was specified. The time integration followed a semi-implicit solver with a time step of $0.2 \mathrm{~s}$. The model was integrated for 20 tidal cycles, the time scale over which the numerical solution reached a quasi-equilibrium state for residual flow and biological variables.

The NPZ model was driven by FVCOM-NH with an initial condition constructed using an analytical steady-state solution (Franks et al., 1986) (Fig. 3). At $t=0, N, P$, and $Z$ vary significantly in the upper $10 \mathrm{~m}$ and then remain constant in the rest of the water column. The vertical profiles of $N, P$, and $Z$ were constructed with the consideration of the observed depth of chlorophyll maxima around $10 \mathrm{~m}$ in Haury et al. (1983) and the depth of pycnocline (Fig. 3). We assumed that $N, P$, and $Z$ are uniform in the horizontal initially, so that all nonuniform distributions of these variables predicted by the model are the result of the biological-physical interactions. To save computational time, the NPZ model was run with a time step of $3.0 \mathrm{~s}$. 

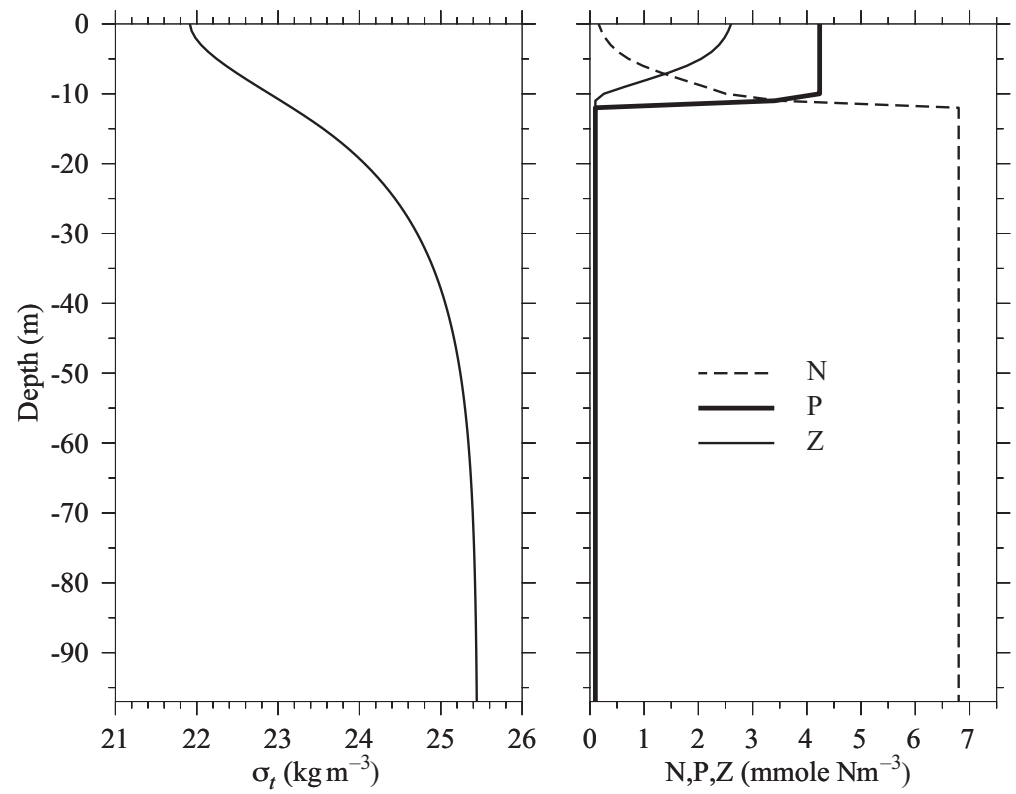

Figure 3. Initial profiles for density (left panel) and biological variables (right panel). The model was initialized using these profiles with an assumption of no cross-isobath variation.

\section{Planktonic responses to internal waves}

FVCOM-NH has captured all of the major features of the generation, propagation and shoaling processes of the internal waves observed over SB and in MB. A detailed description of model results and comparisons with in-situ data was given in Lai et al. (2010b), and the major features are summarized here. The internal waves develop following the three stages as suggested by Lee and Beardsley (1974). A sharp density front forms at the western crest of SB one hour before the transition of the tide from ebb to flood (Fig. 4). This front is advected westward toward the slope with the early flood phase tidal current and then the density depression separates into two packets half an hour later: one trapped on the slope as a geometrically locked hydraulic jump (Chen and Beardsley, 1998) and the other moving offbank with the tidal current. The latter intensifies on its journey and disintegrates into an internal wave packet while propagating toward the coast. The internal waves do not dissipate significantly until the wave packet shoals and approaches the MB shelf (Fig. 5), where the leading density depression of the wave packet becomes comparable to the local water depth. In this process, the isopycnals containing the bottom water are compressed and a strong offshore current with high-frequency cross-isobath variation appears near the bottom. This offshore flow extends over the entire bottom of the slope region $(\sim 5-6 \mathrm{~km})$, with a maximum velocity of $>0.3 \mathrm{~m} \mathrm{~s}^{-1}$. At every $\mathrm{M}_{2}$ tidal cycle, internal waves in $\mathrm{MB}$ appear with a phase speed of $0.56-0.68 \mathrm{~m} \mathrm{~s}^{-1}$, a period of 5-10 minutes, a wavelength of $200-400 \mathrm{~m}$ and a downward displacement of the thermocline of $\sim 30 \mathrm{~m}$. 


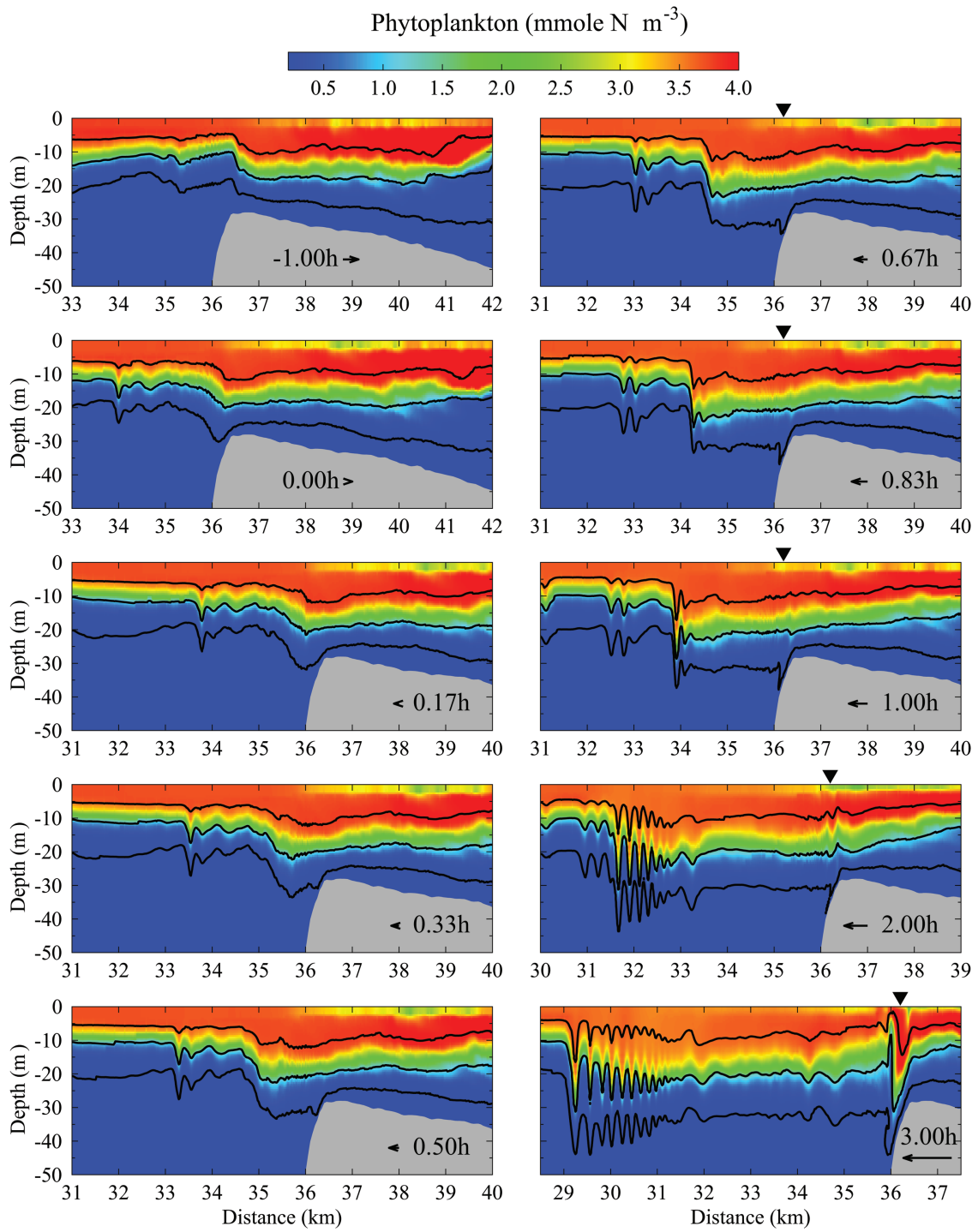

Figure 4. Snapshots of the cross-bank distribution of phytoplankton concentration at $-1.00,0.00$, $0.17,0.33,0.50,0.67,0.83,1.00,2.00$ and 3.00 hours relative to the ebb-flood transition. The negative sign indicates the ebb period. The ebb-flood transition is defined as the time of low tide at the open boundary. Heavy solid lines represent the isopynocal lines of 22.5, 23.5, and 24.5. Black filled downward triangle at surface indicates the location where the hydraulic jump is generated over the western steep slope of SB during flood tide.

Correspondingly, the temporal variations and spatial distributions of phytoplankton biomass follow the isopyncal vertical displacement to the lowest order as the internal waves are generated and propagate westward toward the coast (Figs. 4 and 5). Within the 
Current $\left(\mathrm{m} \mathrm{s}^{-1}\right)$
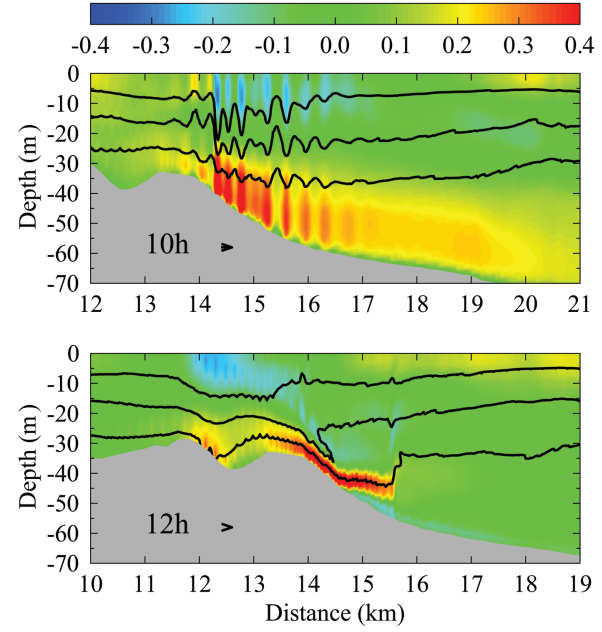

Phytoplankton (mmole $\mathrm{N} \mathrm{m}^{-3}$ )
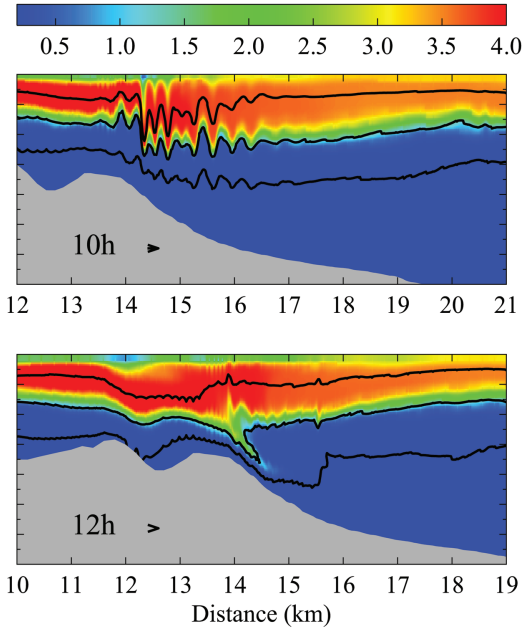

Figure 5. Snapshots of the cross-bank distribution of cross-isobath currents (left panels) and phytoplankton concentration (right panels) at 10 and 12 hours relative to the ebb-flood transition as the internal wave packet shoals and is dissipated over the shelf. The definitions of solid lines and images are the same as those in Figure 4.

wave packet, the phytoplankton tend to oscillate vertically at the same frequency as the waves, while before and after the wave packet passes, the phytoplankton are distributed relatively uniformly in the upper water column. Large vertical displacement and mixing of phytoplankton occurs in the geometrically trapped hydraulic jump over the western flank of the Bank during the maximum flood tide. After the internal wave packet shoals and dissipates over the MB shelf, a strong offshore current forms near the bottom, which brings upper water with high phytoplankton concentration to the bottom (Fig. 5), a process similar to that described by Witman et al. (1993), who found a high production of bottom suspension feeders through a downward food supply resulting from the breaking of internal waves on subtidal pinnacles.

The model-predicted vertical migration of the phytoplankton profile is in good agreement with the observed chlorophyll-a fluorescence (scaled to match the model unit) (Fig. 6). This comparison was made in the middle of the basin, close to the observation site, and the model-computed phytoplankton concentration was selected during the passage of the internal wave packet in the $20^{\text {th }}$ tidal cycle. In general, the vertical distributions of phytoplankton are characterized by a subsurface maximum at around $10 \mathrm{~m}$ depth before the arrival of internal waves. When the waves arrive, the phytoplankton subsurface maximum is shifted downward to the $30 \mathrm{~m}$ depth while retaining the same shape. Over the next two hours, the center of the phytoplankton subsurface maximum gradually moves upward, but in shape it looks more diffused. Around six hours later, the phytoplankton subsurface maximum reappears at $10 \mathrm{~m}$ depth, with a completion of a vertical migration 

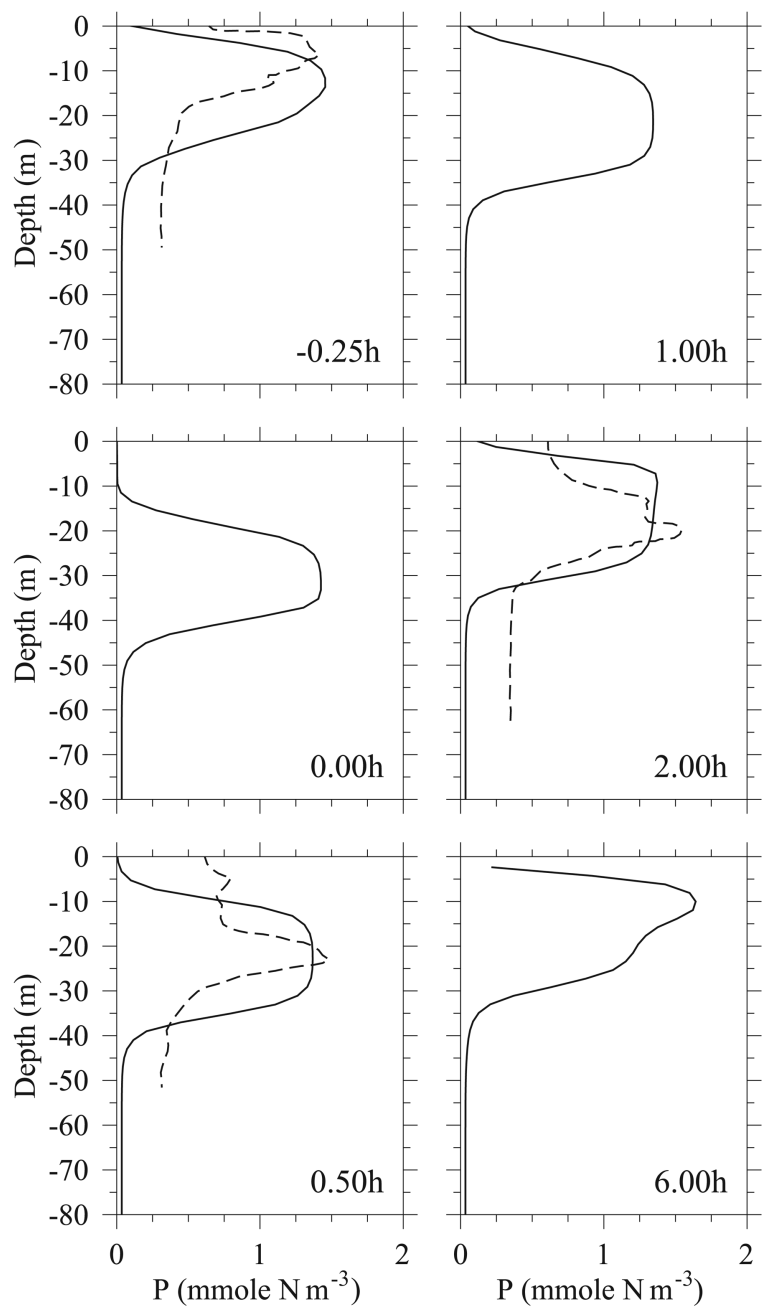

Figure 6. Model-predicted variations of phytoplankton profiles at the time of 0.25 hours before the arrival of waves; 0.00 hour (when the waves arrive); and 0.5, 1.0, 2.0, and 6.0 hours after the waves pass. The model data used in these profiles are from a point in the middle region of Mass Bay. The in-situ data are from Haury et al. (1983) in the same region. The dashed lines are observed chlorophyll-a fluorescence and the solid line is the model-computed phytoplankton concentration. Because no information was given for the data unit, the data digitized from Haury et al.'s (1983) paper was normalized by a factor of 26.0 to match the model unit.

cycle. This vertical displacement pattern was clearly evident in the observed profiles, as indicated by the chlorophyll- $a$ fluorescence subsurface maximum, which matches reasonably well with the model results. The discrepancy in the details of these profiles is acceptable, since the numerical experiment only represents the August climatologic 


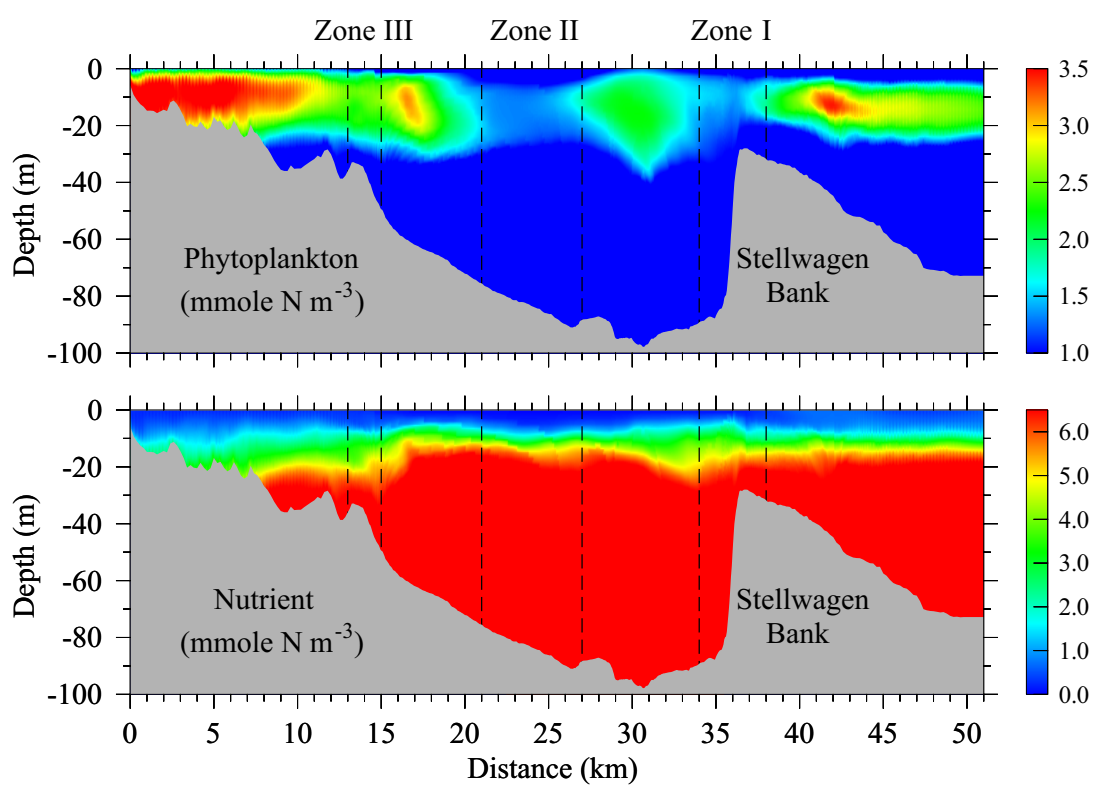

Figure 7. The cross-isobath distributions of phytoplankton (upper) and nutrient (lower) concentrations averaged over the $20^{\text {th }}$ tidal cycle.

average conditions in $\mathrm{MB}$, and the details of observed profiles are related to the particular history of previously passing internal waves (Haury et al., 1983).

The tidally-averaged distribution of phytoplankton (based on the time average of the $20^{\text {th }}$ tidal cycle simulation) is characterized by four distinct subsurface high-concentration patches (Fig. 7). Separating them are three low-concentration zones: (I) the western flank of Stellwagen Bank; (II) the center of Stellwagen Basin (about 21-27 km from the MB coast); and (III) over the transition between the western edge of Stellwagen Basin and the MS shelf (about $15 \mathrm{~km}$ from the MB coast). The subsurface phytoplankton maximum value over the top of the Bank is $\sim 2.0-3.0 \mathrm{mmol} \mathrm{N} \mathrm{m}{ }^{-3}$, which is close to the observed and simulated concentrations in the interior of the Gulf of Maine (Franks and Chen, 2001). Similar values are also found over the MB shelf where the internal waves break and are dissipated. The phytoplankton concentration in the interior of MB around the deepest region is relatively lower and more vertically diffused. In contrast to phytoplankton, the tidally-averaged nutrient concentration maintains a similar vertical distribution across the Bank and MB interior except over the MB shelf. The nutricline is located at around $10-15 \mathrm{~m}$ depth, with the undisturbed high concentration in the deep region.

Historical August chlorophyll data, which were available nearest to the model transect, were collected from the National Oceanographic Data Center (http://www.nodc.noaa.gov) (Fig. 1) and compared with the model-computed tidally-averaged profiles of phytoplankton (Fig. 8). The data were interpolated onto the model section by assuming no along- 

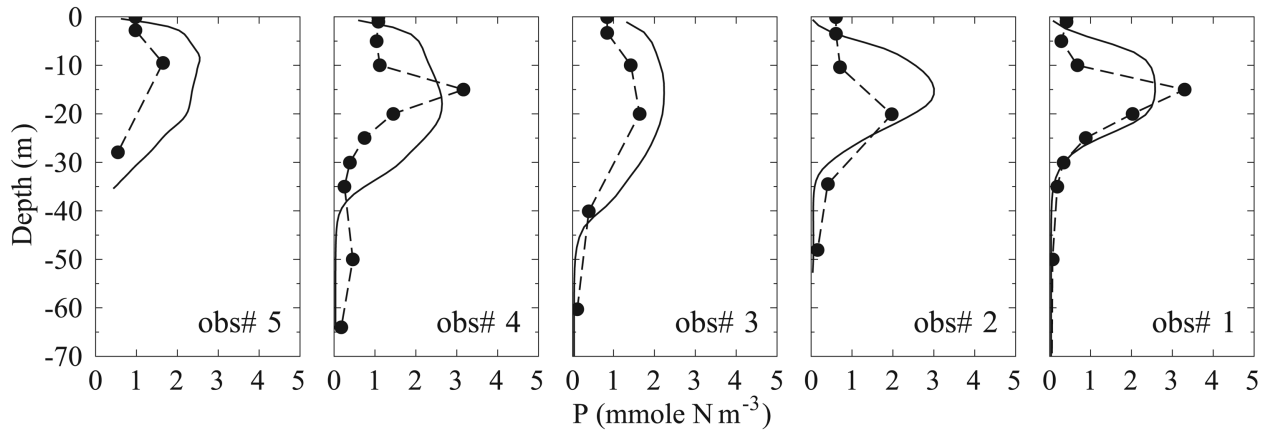

Figure 8. Comparisons of observed (black dot) and model-computed (solid line) phytoplankton profile at observation sites \#1-5. The model data are averaged over the $20^{\text {th }}$ tidal cycle.

isobath variance and the original data unit of $\mathrm{ug} \mathrm{l}^{-1}$ was converted to mmole $\mathrm{N} \mathrm{m}^{-3}$ based on the relationship $\mu \mathrm{g}^{-1} \times 70 / 12 / 6.625=$ mmole $\mathrm{N} \mathrm{m}^{-3}$. In spite of the lack of detailed information about originators and cruises as well as data uncertainties and irregular sample times, the model-computed and observed phytoplankton concentrations show similar distributions and subsurface maxima in both horizontal and vertical directions. At site \#1 off the eastern edge of the Bank inside the GOM, the model-computed phytoplankton concentration shows a subsurface maximum of $\sim 2.5$ mmole $\mathrm{N} \mathrm{m}^{-3}$ from $10-20 \mathrm{~m}$ depth and decreases rapidly with depth from $20-30 \mathrm{~m}$. This pattern is similar to the observed chlorophyll concentration, which shows a sharp subsurface maximum of $3.0 \mathrm{mmole}^{-3}$ at around $15 \mathrm{~m}$. Similar agreement is also seen at sites \#2, 4 and 5. At site \#3 at the western edge of the Bank, the observations show significant phytoplankton concentration spread over the upper $40 \mathrm{~m}$, which is consistent with the more vertical diffusive profile shown in the model. The difference between the model-predicted and observed values of phytoplankton concentration is given in Table 1.

The relatively large difference is understandable, because the biomass of $P$ and $N$ is sensitive to the selected biological parameters and initial conditions. Since this study is focused on the impact of high-frequency internal waves on the spatial distribution of phytoplankton rather than the simulation itself, it does not make sense to tune the parameters to fit the model with the data.

\section{Mechanism for the formation of phytoplankton patchiness}

The patchy distribution of phytoplankton predicted in our coupled FVCOM-NH-NPZ model experiment raises a fundamental question about its driving mechanisms. An

Table 1. Differences between model-predicted and observed values of phytoplankton concentration.

Difference Site \#5

Site \#4

Site \#3

Site \#2

Site \#1

Avg (Model-Obs)

0.78

0.76

0.46

0.54

0.44

Max (Model-Obs)

1.06

1.47

0.90

1.85

1.72 


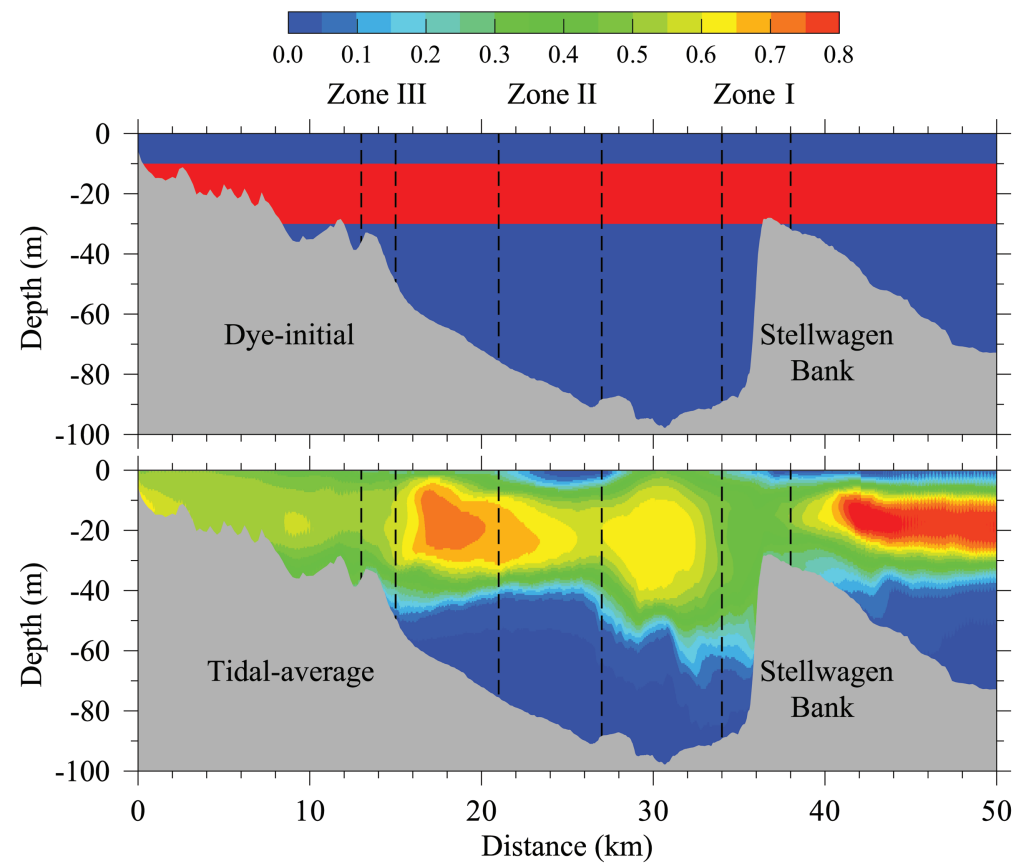

Figure 9. Distributions of the dye concentration at initial time (upper) and averaged over the $20^{\text {th }}$ tidal cycle (lower). At initial time, one unit concentration of dye is injected horizontal-uniformly in the water depths of $10-30 \mathrm{~m}$.

equivalent question here is: why there are three low phytoplankton concentration zones in this system? Are they a result of the response of phytoplankton to purely physical processes or due to biological-physical interaction? To identify and quantify the impact of physical processes, we conducted a passive tracer experiment by injecting a unit concentration of dye uniformly into the upper 10-30 m of the water column (Fig. 9) over the entire computational domain and running the model for 20 tidal cycles with the same setup as our coupled physical-biological experiment.

The tidally-averaged distribution of dye concentration during the $20^{\text {th }}$ tidal cycle is very similar to the model-predicted phytoplankton distribution (Fig. 9). The model predicts regions of low dye concentration over the western slope of Stellwagen Bank (similar to zone I in Fig. 7) and in the interior of MB 21-29 km from the coast (similar to zone II in Fig. 7), suggesting that the low phytoplankton concentration zones shown in Figure 7 are caused primarily by physical processes. In zone I, the model predicts a strong downwelling residual flow of $\sim 0.6 \mathrm{~cm} \mathrm{~s}^{-1}$ and an offshore residual current of $\sim 6.0-8.0 \mathrm{~cm} \mathrm{~s}^{-1}$ over the slope (Fig. 10), which forms a clockwise residual circulation cell with a horizontal scale similar to the width of the slope. It is clear that this cell advects phytoplankton into deeper water, thus forming a low phytoplankton zone in a depth range of $10-30 \mathrm{~m}$. This is also consistent with the hydraulic jump formed during the flood tidal period, which tends to 

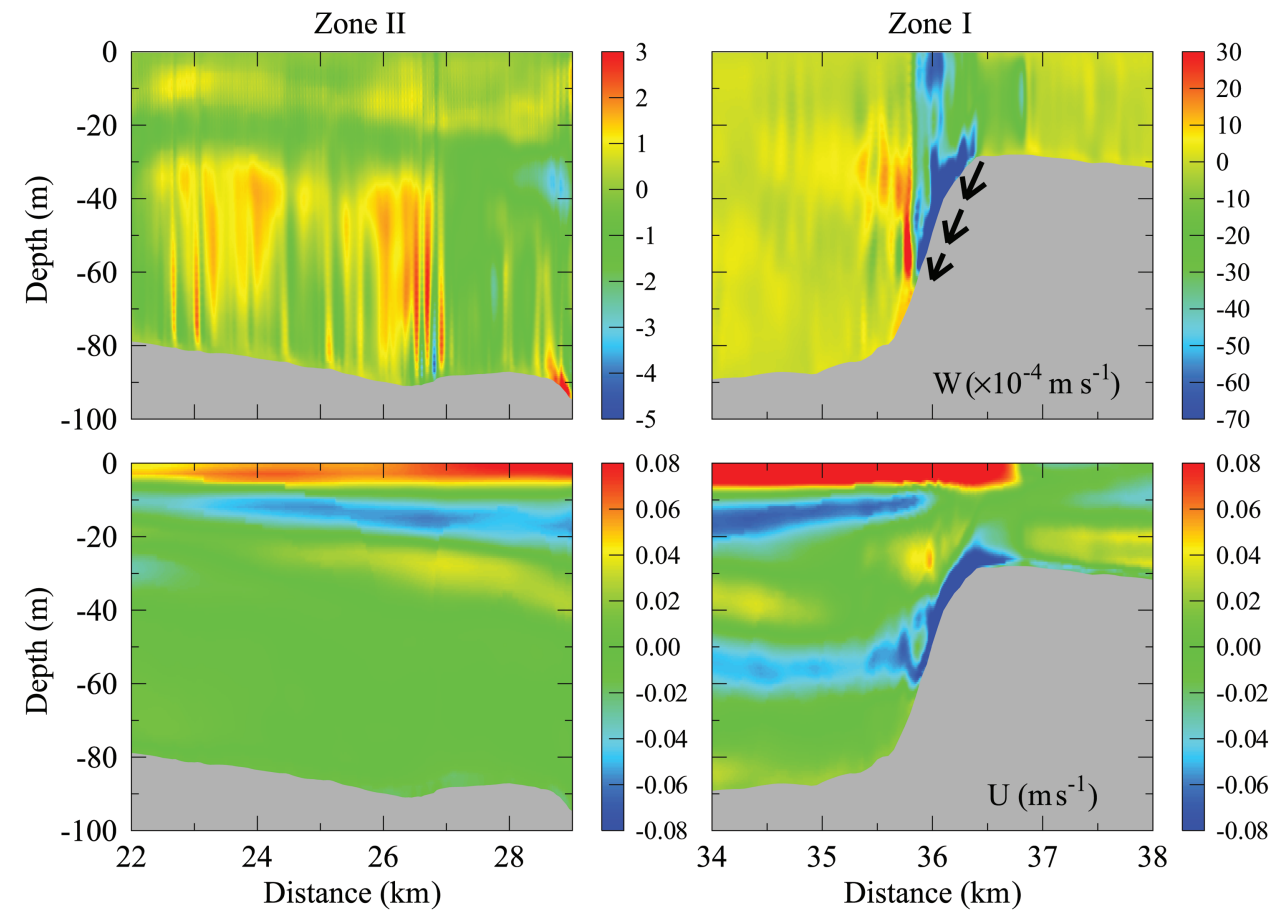

Figure 10. Distributions of vertical (upper) and cross-isobath (lower) velocities averaged over the $20^{\text {th }}$ tidal cycle in zone I (right panels) and zone II (left panels). Vectors in plots illustrate the directions of the currents.

pump phytoplankton downward over the slope (shown in Fig. 4). The pattern of residual vertical and horizontal velocities in zone II does not support the formation of a low dye concentration area in that region (Fig. 10). The relatively strong residual upwelling below $40 \mathrm{~m}$ suggests that there is no mechanism that can transport the dye downward like what we have observed in zone I.

We have examined the interaction of the internal wave packet with tidal currents in zone II and found that this is a critical region in which the high-frequency internal waves start traveling against the tidal currents (Fig. 11). Our model shows that the internal waves form in the early phase of the flood tidal period and then propagate westward toward the coast on the flood tidal current. When the internal waves arrive in zone II, the tide is at the flood-to-ebb transition and the internal waves begin to travel against the ebb tidal current. The nonlinear interaction of the internal waves and offshore tidal current significantly enhances the vertical velocity within the wave packets with an increase in internal wave dissipation. As a result, the dye is carried towards the coast. This process can be seen clearly in Figure 12, which shows the dye distribution before and after an internal wave packet has passed through zone II. Since internal waves form in each tidal cycle and all of 


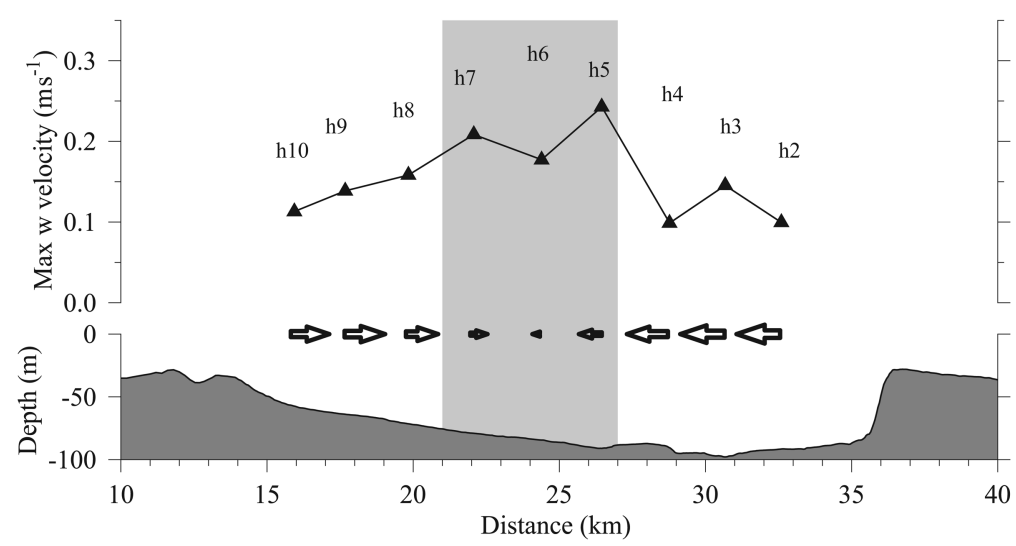

Figure 11. The maximum vertical velocity within an internal wave packet (upper panel) and cross-isobath vertically averaged tidal currents (lower panel) at locations after $2^{\text {nd }}-10^{\text {th }}$ hours from the transition of tides from ebb to flood. The gray area indicates zone II where low phytoplankton concentration occurs.

them travel through zone II at the same tidal phase, the dye concentration in zone II gradually decreases with time.

Unlike in zones I and II, the key mechanism in the relatively low phytoplankton concentration in the MB shelf region $13-15 \mathrm{~km}$ from the coast seems associated with internal wave breaking and subsequent mixing, since very little onshore transport of dye is

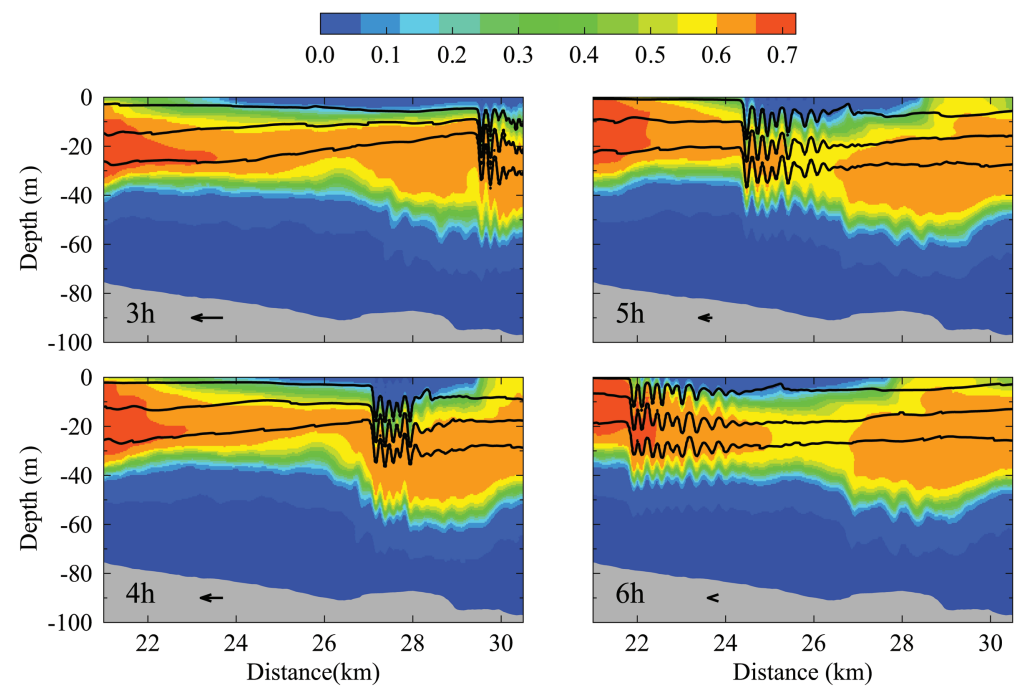

Figure 12. Snapshots of dye concentration before and after the internal wave package passes zone II. The definitions of solid lines are the same as those in Figure 4. 


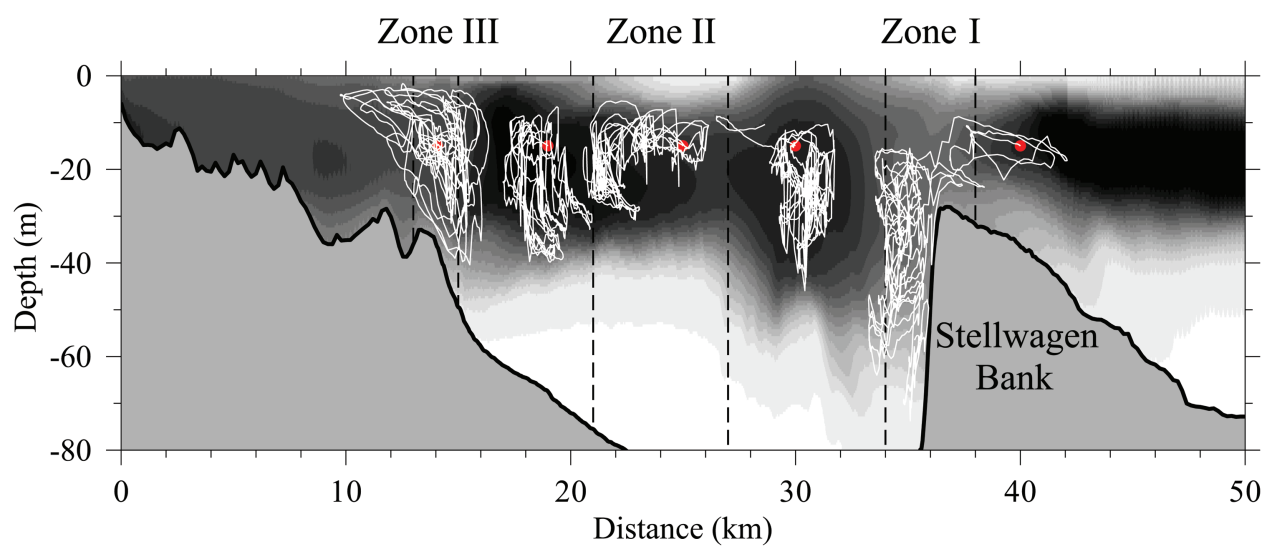

Figure 13. Trajectories of particles released at $15 \mathrm{~m}$ during the 20 tidal cycles. The background image is the averaged dye concentration over the $20^{\text {th }}$ tidal cycle as shown in Figure 9 (lower panel).

detected in Figure 9. The high phytoplankton concentration over the shallow MB shelf shown in Figure 7 is probably driven by biological processes with continuous nutrient supply from the deeper region of Mass Bay.

The dye experiment results are also supported by the Lagrangian particle tracking experiment results shown in Figure 13. The physical features described in zones I, II and III are evident in the particle trajectories. A net onshore Stokes' drift of particle trajectories found in zone II is consistent with the distribution pattern shown in Figure 12 as the wave package passes.

The vertical displacement of isopycnal surfaces within the internal wave packet can significantly increase the vertical nutrient flux from deeper water into the euphotic zone (Fig. 14). Averaging the nutrient flux within the upper 10-30 m water column where the vertical velocity and nutrient fluctuation are strongly related, we found that the passage of the internal wave packet can cause an increase in the instantaneous nutrient flux of two or three orders of magnitude (Fig. 14). In the high phytoplankton regions, the tidal-cycleaveraged net nutrient flux is in the range of $2-8 \times 10^{-4}$ mmole $\mathrm{N} \mathrm{m}^{-2} \mathrm{~s}^{-1}$, sufficient to support the growth of phytoplankton in these patchy areas.

\section{Discussion}

Large-amplitude high-frequency nonlinear internal waves propagate towards the MB coast as a leading edge feature of the internal tides (Gerkema, 1996; Lai et al., 2010b). The hydrostatic version of FVCOM is able to resolve the internal tide, which propagates towards the coast as a single pycnocline depression during the flood tidal period. The question raised here is whether or not the phytoplankton patchy structure detected in the non-hydrostatic FVCOM experiment could also happen in hydrostatic conditions. A 


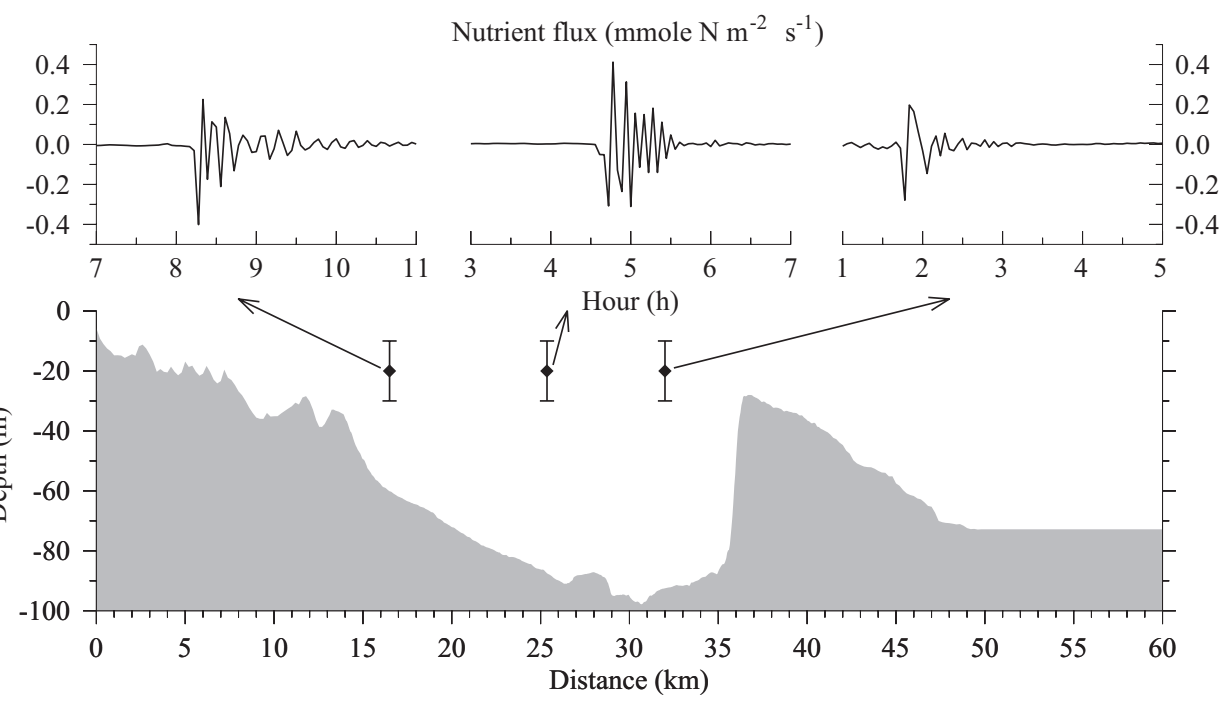

Figure 14. Time series of nutrient flux during the passage of internal wave packets at three sites along the cross-bay transect. These fluxes are averaged over the 10-30 m water column (see text for details).

comparison experiment between hydrostatic and non-hydrostatic FVCOM was made to address this question. The results show that the hydrostatic FVCOM could produce similar patchy structures, but with significant differences in high phytoplankton concentration levels and the locations of the separation zones. For example, at a site in zone II ( $25 \mathrm{~km}$ from the coast), the vertical velocity predicted by the hydrostatic FVCOM is about $40 \%$ higher than that in the non-hydrostatic FVCOM case. As a result, the phytoplankton concentration is higher and spread over a larger vertical scale in the hydrostatic FVCOM than in the non-hydrostatic FVCOM (Fig. 15).

It is well known that the NPZ model is controlled by biological parameters whose values are in a certain range of variation (Frank and Chen, 1996). Is the patchy structure of phytoplankton concentration found in the coupled FVCOM-NH-NPZ model a biased solution due to parameter uncertainty? To address this question, we have conducted a sensitivity analysis with respect to the uncertainty in the biological parameters used in this study. The selected values of the biological parameters are listed in Table 2. Even in the unrealistically large range specified in this experiment, the patchy structure of phytoplankton concentration remains unchanged, although the level of concentration changes in the various cases. An example is shown in Figure 16 for the horizontal distribution of tidally-averaged phytoplankton concentration at a depth of $13 \mathrm{~m}$ in the region between $10 \mathrm{~km}$ and $45 \mathrm{~km}$ of the computational domain over the $20^{\text {th }}$ tidal cycle. In these plots, the primary phytoplankton patches, which are centered near the transition between the MB shelf and Stellwagen Basin $(16 \mathrm{~km})$, in the deepest region of Stellwagen Basin $(30 \mathrm{~km})$ and 


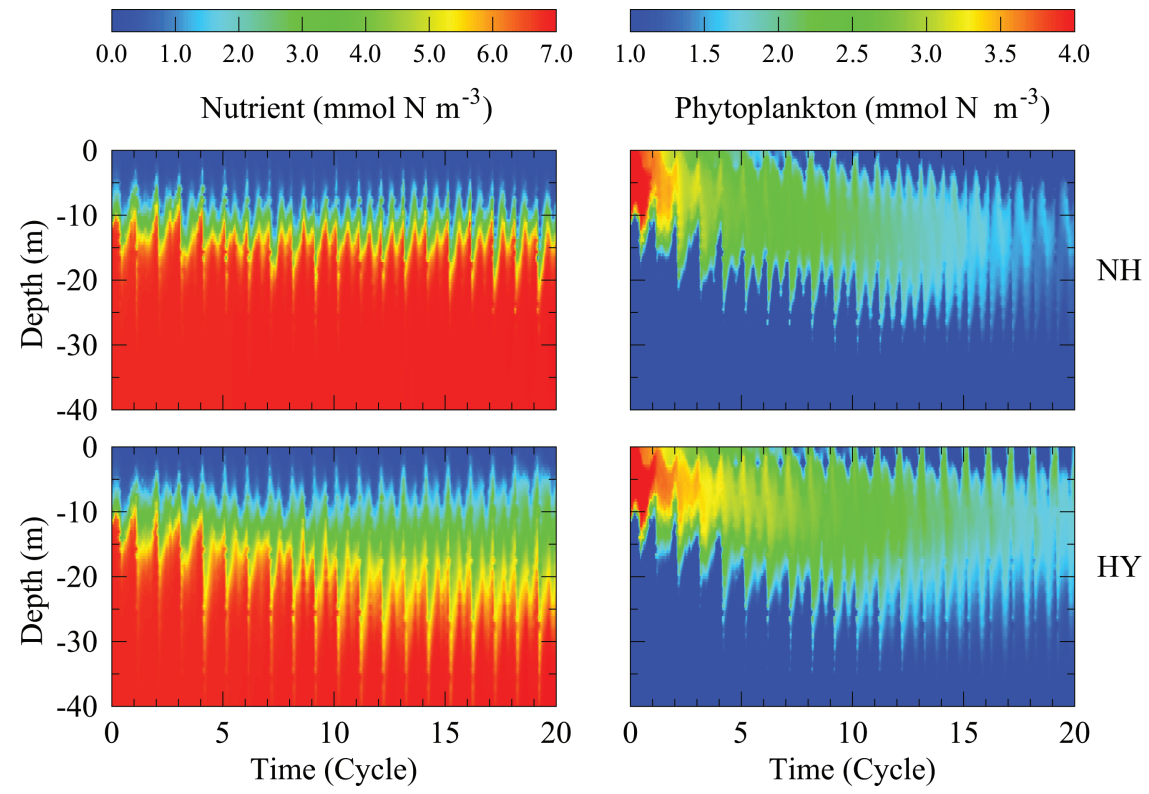

Figure 15. Time series of nutrient (left column) and phytoplankton (right column) concentrations at a point (25 km from the coast) in zone II predicted with non-hydrostatic (upper panels) and hydrostatic (lower panels) dynamics.

on the east slope of SB (42 km), are visible under different sets of biological parameters. This suggests that the model-predicted patchy structure of the phytoplankton concentration is robust.

Table 2. Sets of biological parameters for sensitivity experiments. The description of biological parameters is given in the text.

\begin{tabular}{cccccccccc} 
Case & $\mathrm{N}_{\mathrm{t}}$ & $\mathrm{V}_{\mathrm{m}}$ & \multicolumn{1}{c}{$\mathrm{K}_{\mathrm{s}}$} & \multicolumn{1}{c}{$\varepsilon$} & $\mathrm{R}_{\mathrm{m}}$ & $\mathrm{g}$ & $\lambda$ & $\gamma$ & $\mathrm{K}_{\text {ext }}$ \\
Std & 7 & 2.0 & 1.0 & 0.1 & 0.5 & 0.1 & 0.2 & 0.7 & 0.17 \\
1 & 7 & $\mathbf{1 . 0}$ & 1.0 & 0.1 & 0.5 & 0.1 & 0.2 & 0.7 & 0.17 \\
2 & 7 & $\mathbf{3 . 0}$ & 1.0 & 0.1 & 0.5 & 0.1 & 0.2 & 0.7 & 0.17 \\
3 & 7 & 2.0 & $\mathbf{0 . 5}$ & 0.1 & 0.5 & 0.1 & 0.2 & 0.7 & 0.17 \\
4 & 7 & 2.0 & $\mathbf{2 . 0}$ & 0.1 & 0.5 & 0.1 & 0.2 & 0.7 & 0.17 \\
5 & 7 & 2.0 & 1.0 & $\mathbf{0 . 0 5}$ & 0.5 & 0.1 & 0.2 & 0.7 & 0.17 \\
6 & 7 & 2.0 & 1.0 & $\mathbf{0 . 2}$ & 0.5 & 0.1 & 0.2 & 0.7 & 0.17 \\
7 & 7 & 2.0 & 1.0 & 0.1 & $\mathbf{0 . 2 5}$ & 0.1 & 0.2 & 0.7 & 0.17 \\
8 & 7 & 2.0 & 1.0 & 0.1 & $\mathbf{1 . 0}$ & 0.1 & 0.2 & 0.7 & 0.17 \\
9 & 7 & 2.0 & 1.0 & 0.1 & 0.5 & $\mathbf{0 . 0 5}$ & 0.2 & 0.7 & 0.17 \\
10 & 7 & 2.0 & 1.0 & 0.1 & 0.5 & $\mathbf{0 . 2}$ & 0.2 & 0.7 & 0.17 \\
11 & 7 & 2.0 & 1.0 & 0.1 & 0.5 & 0.1 & $\mathbf{0 . 1}$ & 0.7 & 0.17 \\
12 & 7 & 2.0 & 1.0 & 0.1 & 0.5 & 0.1 & $\mathbf{0 . 4}$ & 0.7 & 0.17
\end{tabular}



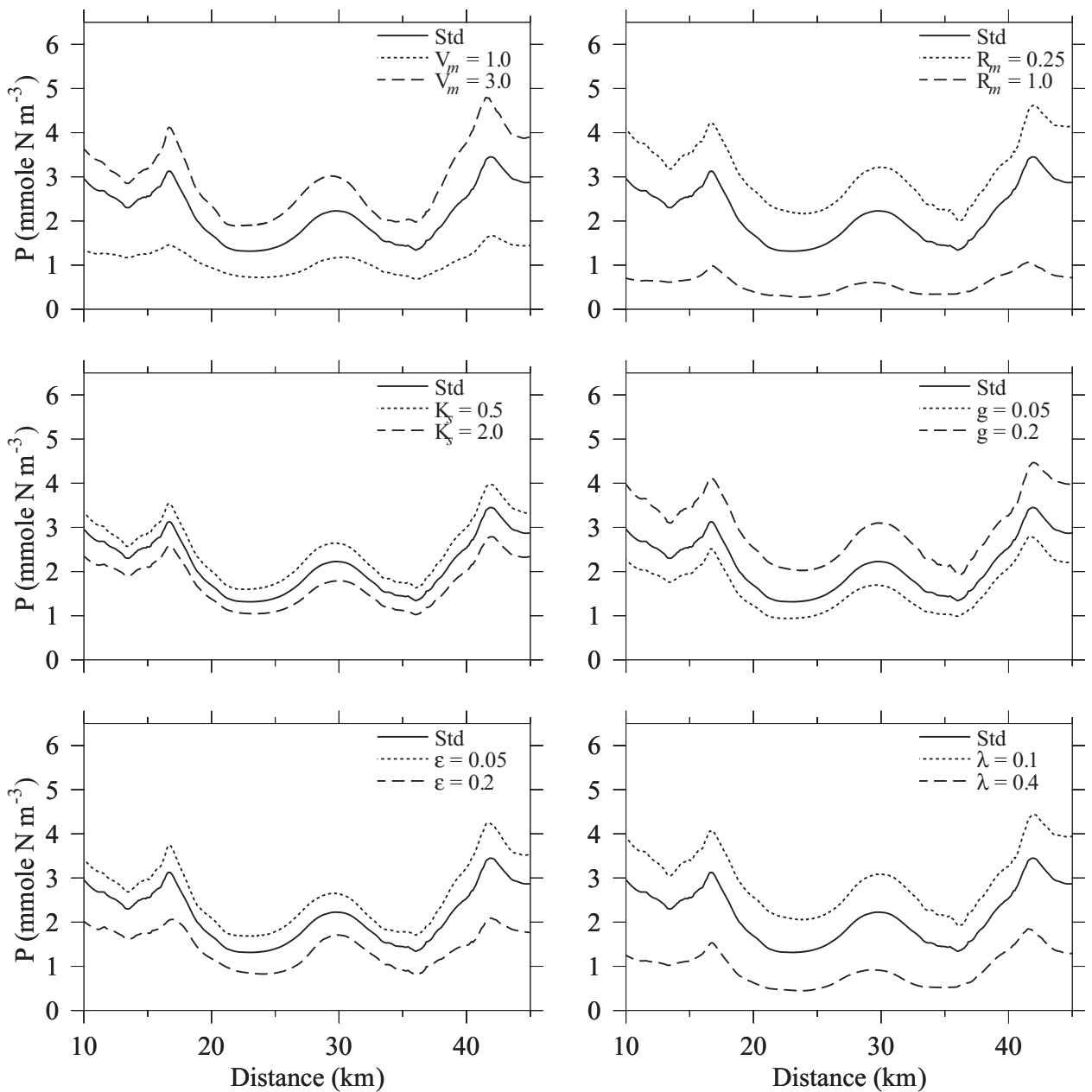

Figure 16. Cross-isobath distributions of phytoplankton concentration at a depth of $13 \mathrm{~m}$ in a region between 10 and $45 \mathrm{~km}$ of the model domain for various selections of biological parameters. The model data are averaged values over the $20^{\text {th }}$ tidal cycle. Definition of each parameter is given in the text.

\section{Conclusions}

A coupled NPZ and FVCOM-NH numerical experiment was conducted to study the impact of large-amplitude high-frequency nonlinear internal waves on plankton dynamics in MB during the stratified summer season. The non-hydrostatic physical model reproduces the major features of high-frequency internal waves that appear in each $\mathrm{M}_{2}$ tidal cycle with periods of 5-10 minutes, wavelengths of 200-400 $\mathrm{m}$ and downward displacement of isopyncals of $\sim 30 \mathrm{~m}$.

The temporal and spatial variability of phytoplankton concentration follows the vertical 
isopycnal displacement to the lowest order as the waves are generated by the semidiurnal tidal flow over SB and propagate westward across MB. After the internal wave packet shoals and dissipates over the MB shelf, a strong off-shelf current tends to bring the high concentration of phytoplankton from the upper water column to the bottom. The tidallyaveraged distribution of phytoplankton is characterized by three distinct zones of low subsurface concentration: (I) the western flank of Stellwagen Bank; (II) the center of Stellwagen Basin; and (III) the steep upper western flank of Stellwagen Basin. The dye experiment suggests that these low concentrations zones are caused by the following physical processes. In zone I, the hydraulic jump that forms during the flood tide produces a strong residual downwelling of $\sim 0.6 \mathrm{~cm} \mathrm{~s}^{-1}$. This downwelling advects phytoplankton into deeper water, thus forming a low phytoplankton region in the depth range of 10-30 m. When the internal waves arrive in zone II, the tide is at the flood-to-ebb transition and the internal waves begin to travel against the ebb tidal current. The nonlinear interaction of internal waves and offshore tidal current increases the vertical velocity within the wave packets, and thus enhance wave dissipation. The dissipative internal waves can carry phytoplankton toward the coast. The relatively low phytoplankton concentration in zone III is mainly caused by wave breaking and dissipation and associated mixing processes.

The MB phytoplankton patch structure also can be produced under hydrostatic conditions, but the resulting phytoplankton concentration is significantly overestimated due to an unrealistic increase in vertical velocity. A sensitivity analysis was conducted for different selections of biological parameters. This analysis indicates that the model-predicted summertime patchy structure of high phytoplankton concentration in MB is robust.

Acknowledgments. This project is supported by NOAA grants DOC/NOAA/NA04NMF4720332 and DOC/NOAA/NA05NMF4721131, US GLOBEC Northwest Atlantic/Georges Bank Program NSF grants (OCE-0234545; OCE-0227679; OCE-0606928; OCE-0712903; OCE-0732084; OCE0726851), and MIT Sea Grant funds (2006-RC-103, 2010-R/RC-116) and NOAA NERACOOS grant NA100558 for the UMassD team, and a NOAA grant (NA-17RJ1223) for R. C. Beardsley. C. Chen's contribution is also supported by Shanghai Ocean University International Cooperation Program (No. A-2302-10-0003), the Program of Science and Technology Commission of Shanghai Municipality (No. 09320503700), the Leading Academic Discipline Project of Shanghai Municipal Education Commission (Project number: J50702), and Zhi jiang Scholar and 111 project funds of the State Key Laboratory for Estuarine and Coastal Research, East China Normal University (ECNU). We want to thank the FVCOM development team members in the Marine Ecosystem Dynamics and Modeling Laboratory, School for Marine Science and Technology, UMassD for their support and assistance in updating and improving the FVCOM code. This paper is \#10-0901 in the SMAST Contribution Series, School for Marine Science and Technology, University of MassachusettsDartmouth, and U.S. GLOBEC contribution number \#683.

\section{REFERENCES}

Balay, S., K. Buschelman, V. Eijkhout, W. Group, D. Kaushik, M. Knepley, L. G. McInnes, B. Smith and H. Zhang. 2007. PETSc user manual. ANL-95/11-Revision 2.3.3., Mathematics and Computer Science Division, Argonne National Laboratory, 190 pp.

Butman, B., P. S. Alexander, A. Scotti, R. C. Beardsley and S. Anderson. 2006. Large internal waves in Massachusetts Bay transport sediment offshore. Cont. Shelf Res., 26, 2029-2049. 
Chen, C. and R. C. Beardsley. 1998. Tidal mixing over finite-amplitude banks: a model study with application to Georges Bank. J. Mar. Res., 56, 1163-1203.

2003. An unstructured, finite-volume, three-dimensional, primitive equation ocean model: application to coastal ocean and estuaries. J. Atmos. Oceanic Technol., 20, 159-186.

Chen, C., G. W. Cowles and R. C. Beardsley. 2006a. An unstructured grid, finite-volume coastal ocean model: FVCOM User Manual. SMAST/UMASSD Technical Report 04-0601, 183 pp.

Chen, C., R. C. Beardsley and G. W. Cowles. 2006b. An unstructured grid, finite-volume coastal ocean model (FVCOM) system. Special Issue entitled "Advances in Computational Oceanography." Oceanography, 19, 78-89.

Chen, C., H. Huang, R. C. Beardsley, H. Liu, Q. Xu and G. W. Cowles. 2007. A finite-volume numerical approach for coastal ocean circulation studies: comparisons with finite difference models. J. Geophys. Res., 112, C03018, doi:10.1029/2006JC003485.

Cowles, G. W. 2008. Parallelization of the FVCOM Coastal Ocean Model. Int. J. High Perform. Comput. Appl., 22, 177-193.

Daly, K. L. and K. O. Smith. 1993. Physical-biological interactions influencing marine plankton production. Annual Review of Ecology, Evolution and Systematics, 24, 555-585.

Evans, M. A., S. MacIntyre and G. W. Kling. 2008. Internal wave effects on photosynthesis: Experiments, theory, and modeling. Limnol. Oceanogr., 53, 339-353.

Falgout, D. R. and U. M. Yang. 2002. Hypre: a library of high performance preconditioners, in Computational Science-ICCS 2002 Part III, Lecture Notes in Computer Science 2331, P. M. A. Sloot, C. J. K. Tan, J. J. Dongarra and A. G. Hoekstra, eds., Springer-Verlag, 632-641.

Franks, P. J. S., J. S. Wroblewski and G. R. Flierl. 1986. Behavior of a simple plankton model with food-level acclimation by herbivores. Mar. Biol., 91, 121-129.

Franks, P. J. S. and C. Chen. 1996. Plankton production in tidal fronts: a model of Georges Bank in summer. J. Mar. Res., 54, 631-651.

2001. A 3-D prognostic numerical model study of the Georges Bank ecosystem: Part II: biological-physical model. Deep-Sea Res. II, 48, 457-482.

Gerkema, T. 1996. A unified model for the generation and fission of internal tides in a rotating ocean. J. Mar. Res., 54, 421-450.

Haury, L. H., M. G. Briscoe and M. H. Orr. 1979. Tidally generated internal wave packets in Massachusetts Bay. Nature, 278, 312-317.

Haury, L. H., P. H. Wiebe, M. H. Orr and M. B. Briscoe. 1983. Tidally generated high frequency internal wave packets and their effects on plankton in Massachusetts Bay. J. Mar. Res., 41, 65-112.

Hibiya, T. 1988. The generation of internal waves by tidal flow over Stellwagen Bank. J. Geophys. Res., 93, 533-542.

Huang, H., C. Chen, G. W. Colwes, C. D. Winant, R. C. Beardsley, K. S. Hedstrom and D. B. Haidvogel. 2008. FVCOM validation experiments: comparisons with ROMS for three idealized barotropic test problems. J. Geophys. Res., 113, C07042, doi: 10.1029/2007JC004557.

Kingsford, M. J. and J. H. Choat. 1986. Influence of surface slicks on the distribution and onshore movement of small fish. Mar. Biol., 91, 161-171.

Lai, Z., C. Chen, G. W. Cowles and R. C. Beardsley. 2010a. A Nonhydrostatic version of FVCOM, Part I: Validation experiments. J. Geophys. Res., 115, doi:10.1029/2009jc005525.

2010b. A Nonhydrostatic version of FVCOM, Part II: Mechanistic study of tidally generated nonlinear internal waves in Massachusetts Bay. J. Geophys. Res. (in press).

Lamb, K. G. 1997. Particle transport by nonbreaking, solitary internal waves. J. Geophys. Res., 102, 18641-18660.

Lee, C. Y. and R. C. Beardsley. 1974. The generation of long nonlinear internal waves in weakly stratified shear flows. J. Geophys. Res., 79, 453-462. 
Le Fèvre, J. 1987. Aspects of the biology of frontal systems. Adv. Mar. Biol., 23, 163-299.

Lennert-Cody, C. E. and P. J. S. Franks. 1999. Plankton patchiness in high-frequency internal waves. Mar. Ecol. Prog. Ser., 186,59-66.

2002. Fluorescence patches in high-frequency internal waves. Mar. Ecol. Prog. Ser., 235, $29-42$.

Maxworthy, T. 1979. A note on the internal solitary waves produced by tidal flow over a three-dimensional ridge. J. Geophys. Res., 84, 338-346.

Pineda, J. 1999. Circulation and larval distribution in internal tidal bore warm fronts. Limnol. Oceanogr., 44, 1400-1414.

Sandstrom, H. and J. A. Elliott. 1984. Internal tide and solitons on the Scotian Shelf: A nutrient pump at work. J. Geophys. Res., 89, 6415-6426.

Sangrà, P., G. Basterretxea, J. L. Pelegri and J. Aristegui. 2001. Chlorophyll increase due to internal waves on the shelf break of Gran Canaria (Canary Islands). Sci. Mar., 65, 89-97.

Scotti, A., R. C. Beardsley and B. Butman. 2007. Generation and propagation of nonlinear internal waves in Massachusetts Bay. J. Geophys. Res., 112, 1-19.

Scotti, A., R. C. Beardsley, B. Butman and J. Pineda. 2008. Shoaling of nonlinear internal waves in Massachusetts Bay. J. Geophys. Res., 113, 1-18.

Shanks, A. L. 1983. Surface slicks associated with tidally forced internal waves may transport pelagic larvae of benthic invertebrates and fishes shoreward. Mar. Ecol. Prog. Ser., 13, 311-315.

Thorpe, S. 2005. The Turbulent Ocean, Cambridge University Press, 459 pp.

Witman, J. D., J. J. Leichter, S. J. Genovese and D. A. Brooks. 1993. Pulsed phytoplankton supply to the rocky subtidal zone: influence of internal waves. Proc. Natl. Acad. Sci. USA, 90, 1686-1690.

Received: 29 January, 2009; revised: 22 September, 2010. 